\title{
SIGMOBI: um sistema de informação geográfica móvel para visualização de rota de entrega de contas de faturamento
}

\section{SIGMOBI: a mobile geographic information system for viewing the billing account delivery route}

DOI: $10.46814 / \operatorname{lajdv2n5-010}$

Recebimento dos originais: 10/07/2020

Aceitação para publicação: 30/08/2020

\author{
Helder Guimarães Aragão \\ Mestre em Sistemas e Computação pela Universidade Salvador (UNIFACS) \\ Instituição: Centro Universitário Estácio da Bahia - Estácio FIB \\ Endereço: Rua Xingu, 179 R. Xingu, 179 - Stiep, Salvador - BA, Brasil \\ E-mail: helderaragao@gmail.com \\ Claudio Luis Vianna \\ Bacharel em Sistemas de Informação pelo Centro Universitário Estácio FIB \\ Instituição: Centro Universitário Estácio da Bahia - Estácio FIB \\ Endereço: Rua Xingu, 179 R. Xingu, 179 - Stiep, Salvador - BA, Brasil \\ E-mail: claudiolavianna@gmail.com \\ Natan Carvalho de Brito \\ Bacharel em Sistemas de Informação pelo Centro Universitário Estácio FIB \\ Instituição: Centro Universitário Estácio da Bahia - Estácio FIB \\ Endereço: Rua Xingu, 179 R. Xingu, 179 - Stiep, Salvador - BA, Brasil \\ E-mail: natanfelipe@gmail.com
}

\section{RESUMO}

Este artigo apresenta o desenvolvimento de um Sistema de Informação Geográfica Móvel (SIG Móvel) para a visualização espacial de rotas de entrega de contas de faturamento do consumo de água de uma empresa de Saneamento. O SIG Móvel desenvolvido neste trabalho proporciona uma visão geográfica da rota de cada funcionário responsável pela entrega das contas de faturamento de água. O trabalho inclui a metodologia de desenvolvimento do SIG Móvel e apresenta os resultados alcançados.

Palavras-Chave: rotas, Sistemas de Informação Geográfica Móvel, geotecnologias.

\section{ABSTRACT}

This paper presents a development of the Geographic Information Systems Mobile (Mobile GIS) for spatial visualization of routes of the water billing account delivery of the sanitation organization. The Mobile GIS developed provides a visualization of geospatial data of this routes. The work includes a methodology of the Mobile GIS development and presents results achieved.

Keyword: routes, Geographic information systems, geotechnologies. 


\section{INTRODUÇÃO}

As concessionárias de serviços públicos realizam, com frequência, a entrega das contas dos seus serviços prestados. A maioria destas concessionárias não possui instrumentos automatizados, que permitam verificar se os funcionários de campo, responsáveis pela entrega das contas, realizaram ou não a entrega (MOURA, 2006). Por diversas razões, uma quantidade significativa de contas é entregue aos usuários dos serviços públicos. Isto gera prejuízos mensais nas receitas das concessionárias, além do transtorno gerado aos usuários. Pode-se constatar que boa parte das empresas carece de um sistema computacional, que possibilite a validação dos problemas de campo reportados pelos funcionários. Estes funcionários que ficam responsáveis pela entrega das contas, muitas vezes, justificam que a rota desenhada pela empresa não condiz com a realidade de campo ou que alguns consumidores não existem. Nos últimos anos, o poder de processamento dos dispositivos móveis aumentou significativamente. Estes dispositivos, atualmente, possibilitam que Sistemas de Informação Geográfica sejam utilizados em tarefas de campo, eliminando o uso de mapas em formato analógico (LONGLEY et. al, 2005). Neste contexto, o presente trabalho aborda a implementação de um Sistema de Informação Geográfica Móvel (SIG Móvel), denominado SIGMobi. Este SIG Móvel permite, aos funcionários de uma empresa de serviços públicos, a visualização de mapas digitais através de dispositivos móveis nas tarefas realizadas em campo. No caso específico deste trabalho, o foco será na tarefa de entrega de contas de faturamento de água.

\section{MATERIAL E MÉTODOS}

Inicialmente foram estudadas diversas tecnologias e plataformas para desenvolvimento de SIG móveis. Após este estudo, foi adotada a plataforma de desenvolvimento Android em função da aderência com a linguagem de programação Java. Além disso, esta plataforma contém um sistema operacional baseado no Linux, bem como uma diversidade de funcionalidades (ANDROID, 2013; LECHETA, 2013). Em seguida, alguns conceitos foram estabelecidos para desenvolvimento do SIG Móvel, denominado SIGMobi:

1) consumidores - são pontos em vermelho no mapa que devem ser visitados;

2) trecho - uma partição indivisível entre os consumidores vizinhos (Figura 1). Cada trecho da rota é representado por uma linha na cor azul;

3) rota - um caminho ou uma sequência de trechos a ser percorrido pelo mensageiro. Toda rota é unidirecional, isto é, só pode ser percorrida em apenas uma direção (Figura 1).

4) consumidor - cidadão beneficiado pelo serviço público; 
5) mensageiro - funcionário responsável pela entrega das contas em campo, seguindo uma determinada rota.

Figura 1 - Exemplo de uma rota.

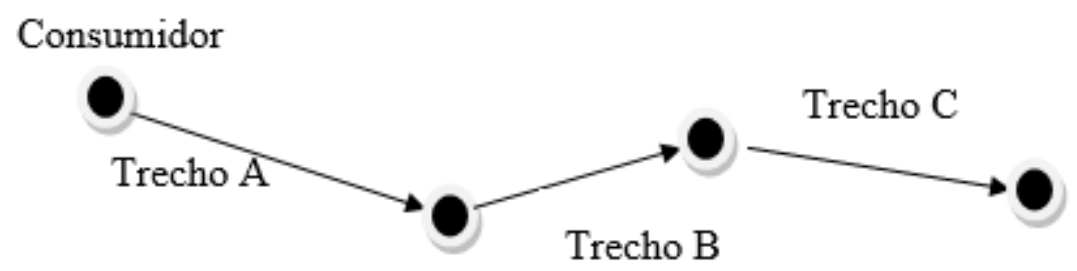

Logo após o entendimento da regra de negócio da aplicação e dos conceitos estabelecidos, ficou definido que o percurso a ser realizado pelo mensageiro seria obtido a partir de um banco de dados da Empresa, que contém a rota a ser percorrida pelo funcionário e os pontos a serem visitados. Após estes entendimentos, partiu-se para a implementação do SIG (CÂMARA, 1996). Nesta fase foram levantados os requisitos funcionais e não funcionais do SIG Móvel. O primeiro tipo de requisito refere-se às funcionalidades do sistema como, por exemplo, cadastrar, executar zoom-in e zoom-out. O segundo tipo de requisito descreve a plataforma necessária para a execução da aplicação móvel. O SIGMobi tem os funcionais e não funcionais listados na Tabela 1.

Tabela 1 - Requisitos Funcionais e Não Funcionais do SIG Móvel.

\begin{tabular}{|c|c|}
\hline REQUISITOS FUNCIONAIS & REQUISITOS NÃO FUNCIONAIS \\
\hline Visualizar Mapa & Executar em Tablets e Smartphones com Android \\
\hline $\begin{array}{c}\text { Executar Zoom-in, Zoom-out, pan e identificação } \\
\text { no mapa }\end{array}$ & Banco de Dados SQLLite \\
\hline $\begin{array}{c}\text { Visualizar os consumidores e a localização atual } \\
\text { do mensageiro }\end{array}$ & - \\
\hline Carregar dados para o dispositivo móvel & - \\
\hline $\begin{array}{c}\text { Descarregar dados do caminho executado em } \\
\text { campo }\end{array}$ & \\
\hline
\end{tabular}

O SIGMobi foi desenvolvido na versão 2.0 da API GoogleMaps e plataforma Android versão 19. Para o armazenamento das coordenadas com os pontos foi utilizado o banco de dados embarcado no dispositivo móvel SQLLite. A Listagem de Código 1 mostra um trecho do código fonte do SIG Móvel. Este trecho de código corresponde à inclusão dos pontos a serem visitados.

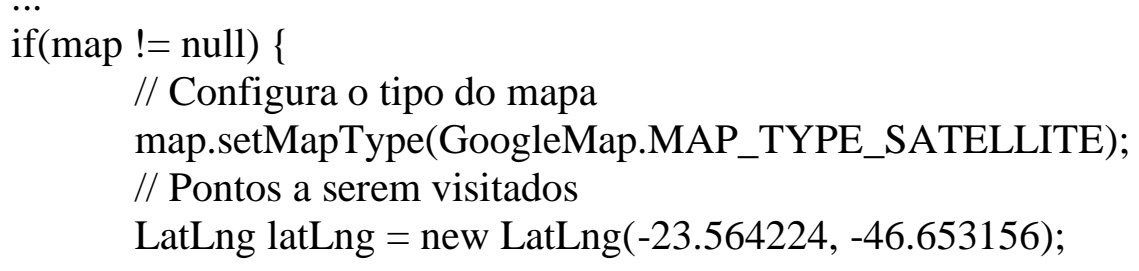


LatLng latLng2 = new LatLng(-23.555696, -46.662627);

final CameraPosition position = new CameraPosition.Builder()

.target(latLng)// Localização

.bearing(0) // Direção em que a câmera está apontando em graus

.tilt(0) // Ângulo que a câmera está posicionada em graus (0 a 90)

.zoom(17) // Zoom

.build();

// Adiciona os marcadores

adicionarMarcador(map, latLng);

adicionarMarcador(map, latLng2);

Listagem de Código 1. Trecho de código da classe MapaPrincipal.java

\section{RESULTADOS E DISCUSSÃO}

Os resultados do desenvolvimento da aplicação móvel podem ser vistos nas telas nas Figuras 2 e 3. A tela do SIGMobi da Figura 2 mostra os pontos em vermelho, que representam os consumidores. Estes são os pontos que devem ser visitados. O ponto em azul é a localização atual do usuário do aplicativo (neste caso o mensageiro). Pode-se perceber que há uma vantagem na visualização espacial dos pontos através do SIG Móvel, pois o mensageiro passa a conhecer previamente quais pontos deverão ser visitados e quais consumidores ele já visitou.

Figura 2 - Uma tela do SIG Móvel.

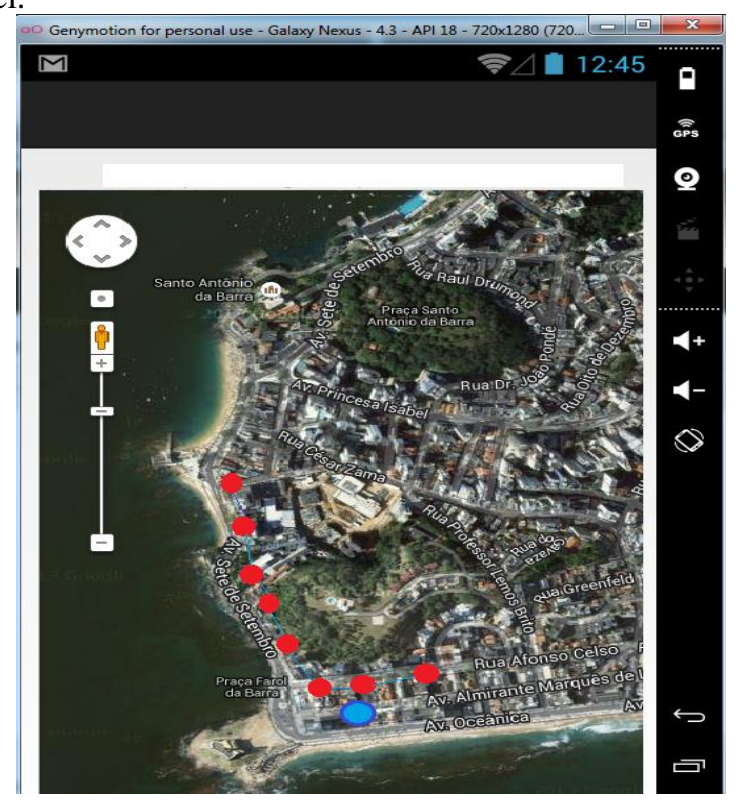

Na Figura 3, pode-se ver outra tela do SIGMobi com o mapa vetorial de uma determinada região. Neste caso, o usuário pode ampliar, ou reduzir, a visão do mapa para melhor visualização e 
alternar entre os mapas vetorial ou matricial (imagem de satélite). O usuário pode, ainda, obter informações, como nome e endereço, ao clicar em cada ponto.

Figura 3 - Exemplo de outra tela do SIG Móvel com mapa em formato vetorial.

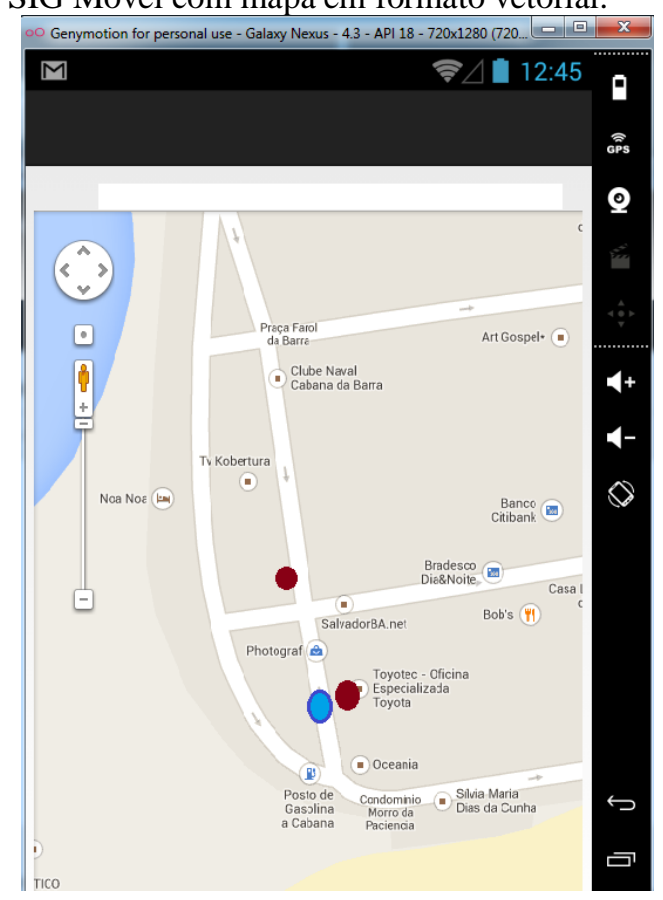

\section{CONCLUSÕES}

O SIG Móvel implementado neste trabalho permitiu a visualização espacial dos pontos de uma determinada rota para entrega de contas de faturamento. A vantagem do uso deste tipo de SIG é a possibilidade de se observar espacialmente os pontos a serem visitados, evitando os possíveis erros nos trajetos que deverão ser cumpridos pelos mensageiros. Outro ponto observável através da aplicação é a presença de obstáculo geográfico, que possa impedir a entrega da conta como, por exemplo, muros ou escadarias em péssimas condições. Tais impeditivos para a entrega de contas podem ser vistos de forma antecipada pelo funcionário. Para trabalho futuro, pode-se destacar o desenvolvimento de um software para computador desktop, visando a análise das rotas armazenadas pelo SIGMobi em escritório. 


\section{REFERÊNCIAS}

Android. Disponível em: <http://www.android.com/>. Acesso em 02/02/2013.

Câmara, Gilberto et al. Anatomia de Sistemas de Informação Geográfica. Editora do Instituto de Computação - Campinas. 1996.

Lecheta, Ricardo R. Google Android: Aprenda a criar aplicações para dispositivos móveis com o Android SDK. Editora Novatec. 2013.

Longley, P., Goodchild, Michael F. e Rhind, David W.. Geographic Information Systems and Science. Editora John Wiley and Sons. 2005.

Moura, Vilidiana Moraes. Modelação Matemática e Sistema de Informação Geográfica como Suporte ao Gerenciamento de Sistema de Abastecimento de Água: subsistema Coophema de Cuiabá/MT. Mato Grosso: Cuiabá, jul. 2006. Dissertação (Mestrado em Física e Meio Ambiente). Universidade Federal

de Mato Grosso. Disponível em:

$<$ http://pgfma.ufmt.br/pagina/index.php?option=com_docman\&task=doc_view\&gid=82>. Acesso em: 02/03/2014. 